\title{
La revista Literatura en el sistema literario español de los años $30^{*}$
}

\section{Literatura Journal in the Spanish Literary System of the 1930s}

\author{
Javier Domingo Martín \\ Universidad Complutense de Madrid \\ domingomartinjavier@gmail.com \\ ORCID iD: https://orcid.org/0000-0002-8196-7146
}

\section{RESUMEN}

Literatura (1934) fue una de las numerosas revistas que conformaron el complejo sistema hemerográfico de la denominada Edad de Plata. Dirigida por Ricardo Gullón e Ildefonso Manuel Gil, que venían colaborando juntos desde 1932, con los proyectos de Brújula y Boletín último, se convirtió en una plataforma para los escritores jóvenes que se iniciaban en la literatura a la sombra de los maestros del 27. En este trabajo, que tiene como punto de partida el epistolario inédito de Ricardo Gullón depositado en la Biblioteca Municipal de Astorga, nos proponemos el estudio detallado de la revista a partir del análisis de sus diferentes discursos (identificador, tipográfico, artístico, mercantil, publicitario, social y literario), su producción y consumo en el sistema literario en que se inserta, así como la situación que ocupa en el contexto de las revistas literarias de la II República y los debates teóricos de los años 30.

Palabras Clave: Ricardo Gullón; Ildefonso Manuel Gil; Literatura; revistas literarias; II República.

\section{ABSTRACT}

Literatura (1934) was one of several journals published during the period known as Spanish "Edad de Plata". It was edited by Ricardo Gullón and Ildefonso Manuel Gil, who were founders of two other magazines during this period: Brújula (1932) and Boletín último (1932). Literatura became an important platform for young writers who wanted to join the masters of the "Generation of '27" in the literary system of the 1930s. In this essay, we will take as a case of study Ricardo Gullón's unpublished letters (settled in Astorga's Public Library), in order to further analyse the place Literatura occupies in the literary journals system from the Second Republic

* Este trabajo se inscribe en el marco de los contratos predoctorales para la Formación de Profesorado Universitario (FPU) que financia el Ministerio de Educación, Cultura y Deporte. Número de referencia: 2016/03916. 
and the theoretical debate taking place during this years, by studying its discourses as well as its production and consumption.

Key words: Ricardo Gullón; Ildefonso Manuel Gil; Literatura; Literary journals; Second Republic.

Ricardo Gullón (Astorga, 1908-Madrid, 1991), además de uno de los críticos españoles recientes de mayor importancia, con relevantes trabajos acerca de la obra de Juan Ramón Jiménez, Benito Pérez Galdós, Miguel de Unamuno y Antonio Machado o sobre aspectos teóricos como la novela lírica (Bockus Aponte, 1975), es una figura clave dentro de la actividad de la generación del 36 antes y después de la guerra (Balcells 2010), así como en el contexto general de la cultura española contemporánea ${ }^{1}$. Junto al periodo santanderino (1941-1958), en que Gullón tuvo una producción crítica y creativa de enorme interés y desempeñó un papel protagonista al frente del movimiento de renovación artística la Escuela de Altamira ${ }^{2}$, son especialmente interesantes los años transcurridos en Madrid durante la década de los 30. Fue entonces cuando el crítico se introdujo en el circuito literario de la capital, de la mano de su maestro Benjamín Jarnés, y llevó a cabo una intensa actividad de dinamización cultural, a través de la fundación y dirección, junto a su amigo Ildefonso Manuel Gil, de tres revistas imprescindibles para comprender las complejas dinámicas poéticas de la anteguerra: Brújula (1932), Boletín último (1932) y, sobre todo, Literatura (1934), síntesis de un proyecto que se había ido ensayando desde Brújula ${ }^{3}$.

Habida cuenta del enorme interés de Literatura (1934) -calificada por algunos como «una de las mejores surgidas en el quinquenio republicano» (Huerta Calvo 2015, xliii), y referida como síntoma de los cambios principales que se estaban llevando a cabo en el periodo republicano en numerosas monografías de referencia (Cano Ballesta 1996, 223)-, sorprende la escasa bibliografía sobre la misma: apenas un acercamiento en una tesis (Sobrino Vegas 2012, 907-920). Esta revista ha tenido, no obstante, mejor fortuna crítica que Brújula y Boletín último. A ello ha contribuido indudablemente la cuidada edición facsímil que de ella hiciera uno de sus impulsores (Gil 1993). Como novedad, para la rea-

${ }^{1}$ Son tres las bibliografías que se han recogido de y sobre Gullón. La más reciente es la de Huerta Calvo y Peral Vega (2010), comentada y organizada temáticamente. Son anteriores las preparadas por Antonio Campoamor (1988) y Ann Marie Brown (1992).

${ }^{2}$ De su labor como crítico de arte en la posguerra, y en concreto en relación con la Escuela de Altamira, se ha ocupado el número 32 de Astorica, coordinado por Miguel Cabañas Bravo y Paula Barreiro López (2013).

${ }^{3}$ En la década anterior, junto a los hermanos Panero, Leopoldo y Juan, y Luis Alonso Luengo, dirigió en Astorga dos revistas de juventud: La Saeta (1925) y Humo (1928), considerada por muchos como una de las primeras revistas del grupo del 36 . 
lización de este trabajo vamos a utilizar los documentos inéditos que alberga el archivo Ricardo Gullón de la Biblioteca Municipal de Astorga, donación de sus herederos en 2003, entre los que se encuentran 3509 cartas, de las cuales 334 se refieren al periodo de interés. La correspondencia con Ildefonso Manuel Gil, en concreto, es la más relevante de todas ${ }^{4}$ : 52 cartas que documentan la historia completa de Literatura y la Pen Colección; así como los avatares creativos del escritor aragonés y del propio Gullón ${ }^{5}$.

Así pues, a partir de un enfoque sistémico centrado en la totalidad de los factores que intervienen en el hecho literario, tal y como se ha venido haciendo en los últimos acercamientos a la revista literaria (Cabañas 2002; Sobrino Vegas, 2012 y 2014), así como desde la comprensión del producto hemerográfico no como un mero repositorio de textos, sino como producto autónomo conformado por un discurso significativo propio (Osuna 1998 y 2004), nos proponemos el estudio de dicha revista a partir del análisis de sus diferentes discursos (identificador, tipográfico, artístico, mercantil, publicitario, social y literario), su producción y consumo en el sistema literario en que se inserta, así como la situación que ocupa en el contexto de las revistas literarias de la II República.

\section{LA BIOGRAFÍA DE Literatura}

Literatura empezó a gestarse durante el año 1933, es decir, tan solo un año después de sus dos proyectos anteriores. El 1 de octubre de 1933 el poeta aragonés le escribe a Gullón: «Estupendo lo de nuestra futura revista. En cuanto yo gane las oposiciones [...] Vamos al papel» $(6 \mathrm{~A} 66)^{6}$. En esa misma carta, además, se definen algunas de las características de Literatura: «Creo más interesante título nuevo y formato de breviario. Ahora bien, temo que así nos resulte demasiado cara. Veremos. Bien, también, lo de dar varias cosas de cada uno».

A comienzos de marzo de 1934 se imprimió el primer número, al igual que Brújula, en la imprenta Galo Sáez. La respuesta de la prensa madrileña no se hizo esperar. El 18 de marzo de 1934, La Libertad incluía un sumario del pri-

${ }^{4}$ El poeta aragonés ha señalado que el proyecto pudo llevarse a cabo por los «viajes de Ricardo a Madrid y una constante comunicación epistolar [que] mantenían en activo nuestra colaboración, con la seguridad de que esta vez no podía haber desacuerdo alguno entre los fundadores y los editores» (Gil 1993, 6)

5 Sobre el epistolario de Ricardo Gullón hemos publicado un artículo en el número 35 de Astorica (Domingo Martín 2016) y la monografía Las secretas galerías de Ricardo Gullón. Lectura crítica de su epistolario (Domingo Martín 2020).

${ }^{6}$ Las 3509 cartas que componen la correspondencia de Ricardo Gullón están repartidas en ocho archivadores diferentes. El código identificativo de cada documento se compone de un número (el archivador), una letra (la carpeta) y otro número que identifica la carta en cuestión. 
mer número y afirmaba: «entre las revistas juveniles de literatura y poesía es muy de señalar la aparición de una que llega bajo los mejores auspicios». El Sol, dos días después, destacaba el esmero en la edición: "Que no se nos olvide que Literatura está pulcramente editada con seriedad, para mostrar así que no están reñidas dichas cualidades con un eficaz modernismo literario. Se nos ocurre exclamar: ¡Ya era hora!» (20-III-1934). Más crítica era la nota del Heraldo de Madrid, en que se indicaba: «Demasiado respetuosos tal vez estos jóvenes con la generación que les antecede. ¿Por qué son ahora las revistas juveniles tan respetuosas?» (8-III-1934).

De hecho, el primer número se abría con un texto del que sería el principal maestro de Gullón y Gil: Benjamín Jarnés. Como la crítica ha señalado, este ensayo hacía «innecesario otro texto programático o editorial de presentación» (Sobrino Vegas 2012, 910), del que la revista carece. A este magisterio explícito se sumaba el de Juan Ramón Jiménez: Enrique Azcoaga escribe un ensayo sobre el moguereño con el título de «Espada de luz» e Ildefonso Manuel Gil dedica sus poemas «A Juan Ramón Jiménez, maestro». Y también se incluyó un poema de Gerardo Diego, en lo que sería costumbre de Literatura: congregar en un mismo espacio a los autores de la generación anterior con los jóvenes.

Completaban el número textos de Pedro Pérez Cloter, Rafael de Urbano y Ricardo Gullón, así como una recensión de revistas que atendía tanto a las grandes publicaciones como a las pequeñas: Revista de Occidente, Cruz y Raya, Isla, Frente literario, Noreste, etc.

Como es de esperar, la correspondencia da cuenta de algunas de las primeras opiniones a raíz de la salida de este número inicial. Rafael Laffón, por ejemplo, tras felicitarle por el primer número, le advierte: «Y mucho cuidado con el derecho de admisión... (¡Cuántos desvelos nos ha causado el mantenimiento del "orden y el rigor" que nos tuvimos que imponer para que Mediodía fuera algo!)» (6A119). Totalmente entusiasta es Pedro Pérez Clotet, quien afirma en repetidas ocasiones que «es, hoy por hoy, la revista joven más entonada y de más firme pulso» (6A191). Ese mismo entusiasmo desde las páginas de otra revista joven, Ágora, en este caso, lo expresa José S. Serna: «Es verdaderamente asombroso este renacer de las letras jóvenes en el medio español»; quien además subraya la vinculación grupal que supone el compartir colaboradores: «El sumario del número primero lo encuentro acertadísimo. Y celebro que varios de esos nombres vayan en el de nuestra Ágora» (6A229). Más críticos son otros corresponsales, como Eugenio d'Ors, quien lamenta el carácter heterogéneo de la revista: «Fuera del trabajo de Benjamín Jarnés y del suyo, todo lo demás se me antoja ajeno al pensamiento articulado y discursivo, salido de una pura vena interjeccional. Los inconvenientes de esta llegan a su colmo, cuando esta vena fluye en un trabajo de intención crítica, como en el titulado "Espada de luz"» (6A154). O Guillermo de Torre, quien le escribe una larga carta señalando los puntos flacos del primer número: «El intento de Literatura lo creeré incompleto -aunque ya sé que por causas no imputables a 
usted- si no pretende llegar a ser una revista más nutrida de elementos, ambiciosa de nuevos enfoques» (6A247).

El n. ${ }^{\circ} 2$ aparecía puntual, aspecto realmente inusual en las revistas pequeñas de la época (Osuna 1983, 44), con una sección crítica notablemente aumentada: firmaban las notas Gullón, Leopoldo Panero, Ildefonso Manuel Gil y Enrique Azcoaga. Se incluían poemas de Jorge Guillén, Alfredo Marqueríe (último Premio Nacional de Literatura por Reloj, como se indicaba en el número), Juan Panero, Luis Torre y Tomás Seral y Casas. Encabezando el número, un poema de Guillén y un ensayo de Ángel Sánchez Rivero acerca de la desorientación del momento presente y de la necesidad de una vuelta a los clásicos ${ }^{7}$. Otros textos fueron un ensayo de María Zambrano, un trabajo sobre André Gide de Gullón, y un comentario de La voz a ti debida, a cargo de Gil.

La prensa, al igual que con el inicial, se hizo eco de la salida de este segundo número. Aparecieron sumarios en El Sol del 22 de marzo y La Libertad del mismo día, donde además se afirmaba: «En esta segunda aparición corresponde sobradamente al interés que en los círculos literarios ha despertado [...] En la desorientación del momento, Literatura puede ser un buen camino para las juventudes que van aflorando a las letras» (22-III-1934).

Entre este número y el siguiente se imprimieron los dos primeros volúmenes de la Pen Colección. Esta colección editorial se había empezado a proyectar, no obstante, desde antes de la salida del primer número: en una carta del 15 de enero de 1934 Jarnés ya se refiere a la posibilidad de publicación de su San Alejo, el que sería el primer número de la colección (6A1) y en otra del 27 de marzo se refiere a la futura colección con el nombre de cuadernos (6A2). El prosista, de hecho, fue una figura esencial, no solo en el proyecto de Literatura, sino también y, muy en especial, en la conformación de Pen. Reflejo de esto es, por ejemplo, una carta del 3 de mayo de 1934 en que le propone a Gullón una primera lista provisional de la colección: «San Alejo, el libro de usted, Telarañas en el cielo, el libro de Vela (hoy mismo pediré el título), Andrómeda y otros mitos, del que escribe, el libro de Manolo Gil y otro libro de usted, el de Maravall, de Seral y Casas, etc.» (6A3). Finalmente, se publicaron los siguientes trece volúmenes: San Alejo, de Benjamín Jarnés (mayo, 1934); Fin de semana, de Ricardo Gullón (mayo, 1934); Meditaciones políticas, de Ángel Sánchez Rivero (julio, 1934); Baladas del Quijote, de Andrés Ochando (septiembre, 1934); Identidad, de Rafael Laffón (octubre, 1934); El futuro imperfecto, de Fernando Vela (diciembre, 1934); La voz cálida, de Ildefonso Manuel Gil (diciembre, 1934); Cóctel de verdad, de José Ferrater Mora (febrero, 1935); A la sombra de mi vida, de Pedro Pérez Clotet (marzo, 1935); Primero de enero, de Jaime Torres Bodet (s.m., 1935); Una lágrima sobre la Gaceta, de Félix Ros

${ }^{7}$ El filósofo del 27 había fallecido en 1930. Fue, pues, un texto póstumo que Literatura publicaba a modo de homenaje (Gil 1971, 1). 
(mayo, 1935); El tiempo manual, de Jorge Carrera Andrade (octubre, 1935); Entre luna y acequia, de Vicente E. Pertegaz (diciembre, 1935).

La selección hacía honor al significado que los impulsores dieron a las siglas del nombre: «Algunos leyeron Pen, y tradujeron por Colección La Pluma. No quería decir eso, sino Poetas, Ensayistas, Novelistas; tratábamos de eliminar el predominio, casi exclusivismo de los poetas, por considerar igualmente legítimo y merecedor de aliento el esfuerzo de los prosistas» (Gullón 1969, 171). De los trece números, pues, cuatro eran de prosa narrativa $(1,2,4,10)$, cuatro de ensayo $(3,6,8,11)$ y cinco de poesía $(5,7,9,12,13)$.

En paralelo a las ediciones Pen, Literatura seguía adelante. Para el n. ${ }^{\circ}$, Gil y Gullón consiguieron, gracias a la acción mediadora de Louis Parrot $^{8}$, un colaborador de excepción:

Te guardo una sorpresa para el 3 quizás... quizás un original inédito de un gran escritor francés. Pero original inédito en absoluto no solo aquí... sino en Francia. No soy mala persona y voy a decirte lo que hay. Louis Parrot va a pedir a MAX JACOB un original inédito para Literatura $(6 \mathrm{~A} 73)^{9}$.

Estos se incluyeron en el idioma original: «Los poemas de Max Jacob -escritos expresamente para L[iteratura] y por tanto absolutamente inéditos- los daremos en francés» (6A75). El epistolario refleja el cuidado de los creadores de la revista por mantener un equilibrio entre los diferentes géneros («si publicamos el cuento de Trincado resulta demasiada narración»), así como de las firmas incluidas: «Creo y Leopoldo [Panero] está conmigo que no debemos dar todavía lo de Urbano. Que es una repetición de firma que todavía no precisamos» (6A74).

En este número, entonces, además de la habitual sección de notas (en que se incluía una dura crítica de la última novela de Antonio de Obregón), aparecían relatos de Ramón J. Sender, que abría el número, Ildefonso Manuel Gil y Ricardo Gullón; poemas de Max Jacob, Vicente Aleixandre, Leopoldo Panero y Francisco Valdés; y ensayos de José Antonio Maravall y Louis Parrot.

Con este número Literatura se vio finalmente consagrada. Una carta de Pedro Pérez Clotet del 28 de mayo así lo refleja: «Creo que habéis logrado llegar a un sereno grado de perfección, que hace de vuestra revista la mejor publicación juvenil actual» (6A192). Del mismo modo que Rafael Laffón, que incluso le comenta la posibilidad de volver a impulsar Mediodía: «El alto ejemplo de ustedes tiene, además, una fuerte sugestión verdadera. Es posible

${ }^{8}$ En el número anterior Leopoldo Panero había reseñado el poemario Misery Farm de Parrot, a quien conoció personalmente en 1932.

${ }^{9}$ También se proyectaba la inclusión de un dibujo del autor, pero finalmente solo se incluyeron versos: «Louis Parrot nos gestiona un dibujo inédito de Max Jacob. Sería formidable y sensacional» (6A74). 
que [ilegible] yo me imponga el sacrificio de reactivar a Mediodía, si encuentro aquí uno, al menos, que me ayude» (6A122).

Como destaca el propio Gil, «los elogios a la continuidad y progresos de la revista no procedían ya solo de las páginas literarias de los diarios madrileños o de las revistas juveniles» $(1993,8)$ : aparecían en periódicos como el Diario de Tarragona, que reseñó, en catalán, el tercer número. En Luz aparece también, el 18 de junio, un largo artículo de Benjamín Jarnés sobre la revista, en el que destaca, sobre todo, la independencia del grupo (Gil 1934, 3).

En el número cuatro se hizo efectiva una determinación que había acompañado a los creadores de la revista desde su número inicial: la incorporación de material gráfico. Así, se abría con un ensayo de Benjamín Jarnés sobre Norah Borges en el que se incluía la reproducción de dos cuadros de la pintora. La Pen Colección tuvo, asimismo, una gran presencia en este número: los hermanos Panero reseñan los dos primeros volúmenes de la colección; Andrés Ochando y Ochando publica un capítulo de Baladas del Quijote (Pen 4); y Rafael Laffón ofrece un adelanto de Identidad (Pen 5). Además de estos textos, se incluyeron poemas de José María Alfaro, Ildefonso Manuel Gil y José Ramón Santeiro, todos en la línea neorromántica. Del lado de la prosa se publicaron textos de José Luis Sánchez Trincado (un cuento de tono humorístico), y los ensayos de José Antonio Maravall (sobre Bergamín ${ }^{10}$ ) y Rafael de Urbano. La sección de reseñas fue la más extensa hasta el momento (en este número se incluían siete críticas en total, sobre libros de Charles Péguy, Ramón J. Sender, Alfredo Marqueríe, José María Pemán, Nicolás Martín Alonso y, como decíamos antes, los autores de los dos primeros Pen: Jarnés y Gullón). Las reseñas en prensa-Informaciones y Heraldo de Madrid-subrayaban la inclusión de los grabados de Norah Borges y el papel tutelar de Jarnés, que iniciaba el número: «No cejan en su alto empeño los jóvenes de Literatura (agosto) bajo la sombra de su "mayor" Jarnés [...] Hay que hacer un elogio a la continuidad de la revista, que supone el esfuerzo y vocación de sus animadores» (13-XI-1934).

En el otoño de 1934 el proyecto llegaba a su fin. Como afirma Ildefonso Manuel Gil: «mantener económicamente la revista era demasiado para una sola persona, de modo que los enormes sacrificios hechos por Ricardo no podían continuarse» $(1993,9)$. El cuaderno final se abría con un extenso artículo de Louis Parrot, al que había visitado recientemente junto con Leopoldo Panero ${ }^{11}$. Se publicaban poemas de Arturo Serrano Plaja, Ildefonso Manuel Gil, José María Morón, Pedro Pérez Clotet y una pequeña pieza teatral firmada por Ramón

10 De este autor, de hecho, se iba a incluir un texto en la revista, pero finalmente nunca llegó a publicarse: «Bergamín me enviará un original. ¿Qué te parece?», le promete Gil (6A77).

${ }^{11}$ Sobre este artículo se hizo una separata, como le informaba Gil a su amigo en una carta: «Parrot me habló de que él iba a publicar un largo ensayo del que se haría separata y que él daría a cambio algo de dinero para la edición» (6A85). 
Gaya y Antonio Sánchez Barbudo. Además, se recogían ensayos de Gullón sobre Franz Werfel, «Visita a Hégel», de José Ferrater y Mora y «En cal viva», un escrito de Benjamín Jarnés sobre Maruja Mallo, de la cual se incluían reproducciones de dos cuadros y un dibujo. La sección de notas se dividió en dos partes: «Libros franceses» (obras de Marie Anne Conmène, René Trintzius y Jean Prévost); y «Libros españoles». En esta última, se reseñaron obras de Ramón J. Sender, Louis Parrot en traducción de José Antonio Maravall y José Luis Sánchez Trincado. Se incluía la crítica de los dos últimos Pen (4 y 5), así como del último volumen publicado de las Ediciones Cierzo, línea editorial asociada a la revista Noreste. El número se cerraba con un texto Gullón en que lamentaba la desaparición de algunas revistas jóvenes (Isla, Ágora, Azor) y un «Índice del tomo I», una relación de todos los autores que habían publicado en Literatura.

La intención de este último número, en cualquier caso, no era abandonar el proyecto. Los dos amigos siguen planeando la salida del próximo número, la prensa sigue hablando de Literatura (Heraldo de Madrid e Informaciones de enero de 1935) y los diferentes amigos con los que Gullón se cartea preguntan por el próximo número: «Mi estimado amigo: ya ha pasado la mitad del 35 y no ha salido Literatura. ¿Se ha suspendido por completo? Si es así, cuánto lo siento. Quedará reducida la preciosa colección a un año» (Valdés, 6A294). Todavía el 19 de febrero de 1935 Gil se refería, aunque por última vez en las cartas conservadas, a números próximos: «No tengo nada para el próximo L[iteratura]. Además creo que debo dejar de publicar en algún número. Piensa que he sido yo la firma más repetida. Al otro sí daré algo y si tengo prosa "en condiciones" prosa daré» (6A97). Sin embargo, Gullón no podía seguir costeando él solo la revista y el proyecto, a falta de financiación, llegó a su inevitable punto final.

\section{El DisCURSO HEMEROGRÁFico DE LITERATURA}

Hemos definido, pues, la configuración de Literatura en su discurrir diacrónico, desde que Gil y Gullón empezaron a concebir la idea hasta su inevitable desaparición. Analizaremos ahora la revista desde un punto de vista sincrónico; esto es, estudiaremos cuál es el discurso hemerográfico de Literatura, «el discurso total de la revista» (Osuna 1998, 21), a partir del análisis de los siete subdiscursos semióticos diferentes de que se compone: identificador, tipográfico, artístico, mercantil, publicitario, social y literario -al que más atenderemos, por ser el más significativo en el caso del producto estudiado-. La significación de la revista, producto autónomo constituido por cinco unidades interrelacionadas, resulta, pues, del entrecruzamiento de todos sus discursos. 


\subsection{Discurso identificador y tipográfico}

De entre los diferentes elementos cuya función es identificar Literatura frente a otras revistas contemporáneas destaca por encima de todos su significativo título. Así lo justificaba Ricardo Gullón: «El título implicaba una toma de posición frente a ciertas ideas de la generación precedente. Gerardo Diego, portavoz de ella, había extremado la oposición entre poesía y literatura, condenando a cuanto apareciera contaminado de esta última. La condena nos pareció desmesurada y esterilizante» $(1969,171)$. La crítica ha interpretado el título del mismo modo: «De la "depuración", método que actúa por eliminación, se pasa a un ideal integrador. La palabra "literatura" deja de ser un término peyorativo frente a "poesía", de modo que dos jóvenes escritores, Ildefonso Manuel Gil y Ricardo Gullón, en 1934 no dudan en llamar Literatura a su nueva revista poética» (Cano Ballesta 1996, 223).

La revista careció de manifiestos y editoriales. Sin embargo, la posición inicial en el número uno del «Ejercicios», de Benjamín Jarnés, reconocido maestro de los editores, ha sido reconocido como tal (Sobrino Vegas 2012, 910). En él, el novelista defiende una literatura entrañada en la vida («la novela es el potente resonador de un haz de vibraciones humanas»), en oposición a las nuevas orientaciones políticas de la literatura («gran parte de la producción literaria española de estos días viene padeciendo un fuerte amago de fiebre política»), así como en contra de las escrituras vanguardistas de principios de siglo («y, ¿qué siglo no padece algún periodo infecundo, en que la técnica pretende salvar la falta de expresión original?»).

La tipografía usada fue un claro sello de identidad de la revista. La sobriedad del diseño - que, en parte, era consecuencia de un presupuesto limitadocontrastaba con lo que sería habitual en las revistas anteriores, como Ultra o Litoral, y se mantenía en coherencia, finalmente, con la significación del título y con la actitud predominantemente rehumanizadora que, como veremos, imperaba en sus metatextos. Se utilizó un solo tipo de letra, con una triple variación de tamaño (título, cuerpo de la revista, sección de «Notas») y un mismo color, negro, con uso de la negrita para los títulos y redonda para el resto. La portada, en tono azulado, siguió esta misma línea: el título arriba, con el número en cuestión; debajo, el mes de publicación y el lugar. La única decoración era una doble raya negra, a modo de marco. El centro quedaba en blanco. La contraportada incluía un escueto sumario, el precio de la revista (una peseta) y el domicilio social. Fue excepcional el número final de la revista, que incluía en el interior del producto un «Índice del tomo I», con la relación completa de los textos incluidos en la serie. En el colofón de cada número se incluían a pie de página (para no emplear una página adicional) los datos de la imprenta madrileña Galo Sáez.

Cada número estaba compuesto por 40 páginas, salvo el primero de $32 \mathrm{y}$ el 5-6, doble, de 80 más cuatro para el índice final. Se usó un papel satinado 
grueso, de 16x24'5 cm. La revista siguió un plan muy bien definido. El 1 de octubre de 1933, por ejemplo, se había concebido el primer año en su totalidad: «porque lo que nos interesa es cubrir la etapa $1^{\text {a }}$ de 6 números y después hacerla mensual a base de suscripciones» (6A74), y la continuación del proyecto en un segundo año, que nunca llegaría, condicionó algunas de las decisiones. Por ejemplo, esperaron al séptimo número para una ampliación del número de páginas: «Aumentaremos las páginas -64(?)- y el precio. Por eso si ahora damos más de 40 páginas no habrá luego justificación al aumento de precio. Hazme caso y verás. La revista con 40 páginas queda hermosa» (6A74).

En el n. ${ }^{\circ} 3$ se produjo un cambio en la domiciliación de la revista: de la madrileña calle Hortaleza, 82, a la localidad zaragozana de Daroca, donde pasó a residir Ildefonso Manuel Gil. Esto provoca una cierta descentralización del producto hemerográfico -aunque su punto de producción y consumo más importante siga siendo Madrid, expande su venta hacia Aragón ${ }^{12}-\mathrm{y}$, sobre todo, un cambio de rol en la figura Ildefonso Manuel Gil, con una actividad especialmente intensa en los comienzos de la revista, cuando residía en Madrid, pero que se va reduciendo según la revista llega a su final. Esto también repercute en cierta pérdida de protagonismo de Gil en la vida literaria de la capital, frente a Gullón, plenamente inmerso en ella. Véase como ejemplo de esto el siguiente fragmento de una carta que le escribe Gil a su amigo el 8 de mayo de 1935: «Leí tu nombre entre los asistentes al banquete a Aleixandre. Eres "gente". ¿Dirás a Leopoldo [Panero], a Parrot y a Maravall que me escriban? Y tú perdona mi tardanza y escríbeme mucho y pronto. No puedes imaginar, querido Ricardo, lo que necesito tu carta» (6A99).

\subsection{Discurso artístico}

La introducción de material gráfico fue uno de los principales deseos de los editores de la revista. Ya en el número inicial se incluía una ilustración de uno de los poemas de Ildefonso Manuel Gil a cargo de Francisco Javier Ciria. Esta amplifica el tema del texto (la imposibilidad del encuentro con la amada: «En vano quiero coger una sonrisa / tuya, o una mirada tuya»), e introduce la imagen de la mujer-guitarra, inexistente en el poema. Fue este el único caso de poema ilustrado en la revista, ejemplo de la relación estrecha entre palabra e imagen que puede darse en las revistas literarias. Para el número 3 se había proyectado la reproducción, nunca realizada, de dibujos de Max Jacob y Villanueva (Gil, 6A37). Finalmente, en los números 4 y el doble 5-6 aparecieron reproducciones de cuadros de Norah Borges y Maruja Mallo, respectivamente,

12 De hecho, Gil, en la introducción a la edición facsímil de Literatura afirma: «La inclusión de Literatura en esta serie facsimilar de revistas literarias aragonesas está muy justificada» $(1993,11)$. 
siempre en blanco y negro. De la primera se reprodujeron dos óleos: una sirena sobre un fondo de formas geométricas, y una pareja, con el título de «Urbano y Simone». De Mallo se incluyeron reproducciones de un dibujo basado en formas geométricas y dos óleos de corte surrealista («Espantapájaros» y «Campanario»), centrados en la representación del fragmento corporal y la acumulación de imágenes mortuorias. En ambos casos se insertaban dentro de sendos ensayos de Benjamín Jarnés sobre la obra de dichas artistas: «Un clima pictórico»y «En cal viva».

Los dos ensayos asimilan la pintura de ambas autoras a la concepción estética que él mismo defendía para la literatura en el texto que abría la serie, «Ejercicios». Así, en el primero interpreta el serafismo de Borges como uno de esos ismos que «acaba siempre [...] por ingresar en los ejércitos de la mística». Es por ello que «durante el torbellino [de las vanguardias] Norah Borges se mantuvo sentada en su angélico peldaño», aunque no deja de reconocer que, en sus pinturas, «algún espíritu ardiente echaría de menos la vida» (n. ${ }^{\circ}$ ). En el caso de Mallo, pintora en la órbita del surrealismo, la crítica es parecida: «la interpretación alta, profunda, del misterio humano», en cuya pintura «se ve al hombre como por los rayos equis» y supone, en fin, «una interpretación profunda del supremo realismo humano», aunque «sin perder sentido plástico, sin perder el sentido constructivo» $\left(\mathrm{n} .^{\circ} 5-6\right)$.

\subsection{Discurso mercantil y publicitario}

Como era habitual en las revistas pequeñas de la época, el principal escollo inicial fue el económico. El 18 de diciembre de 1933 Gil se pregunta: «La revista estupenda como tú la planeas. Algo muy serio pero que no es posible hacer. ¿De dónde vamos a sacar tantísimo dinero?» (6A67). Finalmente, como es bien sabido, Gullón se haría cargo de todos los gastos una vez que obtiene su plaza como fiscal en la Audiencia Provincial de Soria, situación de la que Gil se lamenta reiteradamente en el epistolario: «Es una lástima que mi situación sea un obstáculo tan grave para la buena marcha de la revista. Para ti solo es una enormidad de dinero» (6A70).

$\mathrm{Y}$ aunque los datos de ventas fueron favorables, dentro de las aspiraciones de distribución de una revista pequeña, no pudieron en ningún caso compensar los gastos ${ }^{13}$ : «El éxito de Literatura es definitivo. Juzga por esto: del primer número se han vendido: 10 en Espasa, 16 en Sánchez Cuesta y 12 en Fe. O sea, agotada en los tres sitios» (6A73). Lo que le permite concluir, quizás con

${ }^{13}$ Sobre el segundo número tenemos los datos concretos de costes de imprenta, que debieron ser, en cualquier caso, similares para todos los de la serie: «La imprenta ha costado $315 \mathrm{p}$ [ese]t[a]s, no 325 como tú decías. En cambio en el papel te equivocaste de menos. Ha costado 62,75. En total, pues, 377,75» (Gil, 6A72). 
demasiado entusiasmo: «Es la que más se vende. Creo que si llegan a salir los cuadernos $^{14}$ L [iteratura] va a constituir un movimiento literario de gran trascendencia» (6A73). Sobrino Vegas señala que la revista «alcanzó una estimable difusión de 500 o 600 ejemplares por número» $(2012,908)$, cuando lo normal en una revista pequeña de estas características era de 200 (Osuna 1983, 200). No obstante, hay que tener en cuenta que la revista se movió principalmente por Madrid, de lo que, por cierto, se queja alguno de sus colaboradores ${ }^{15}$.

Por todo ello, se hacía apremiante conseguir financiación externa. El 11 de noviembre de 1934 le escribe Gil a Gullón: «[i]Por qué no mandas hacer en la imprenta unos boletos de suscripción en los que se diga cómo se ha sostenido L[iteratura] durante un año a costa de sacrificios y cómo al empezar el nuevo año necesita la ayuda mediante suscripción de los que crean que L[iteratura] representa algo en la vida literaria española?» (6A86). Lamentablemente, carecemos de datos concretos sobre las suscripciones para valorar con exactitud la implicación económica de este factor, que en ningún caso sería suficiente para la continuidad de la revista.

Es relevante señalar la voluntad expresa de los editores por mantener la independencia económica $\mathrm{y}$, en consecuencia, la libertad total en la dirección de la revista, de la que habían carecido en Brújula, cuyo equipo directivo estaba fuertemente polarizado en dos grupos enfrentados (Gil 1993, 4-5). Es por ello que, en contraste con lo que ocurría en todas las revistas anteriores -con la excepción evidente de Boletín último, sin pretensiones de continuidad-, Literatura careció en su totalidad de anuncios. Rechazaron, del mismo modo, algunas opciones que pondrían en riesgo su independencia: «Esto sería mejor que buscar una fuerte ayuda económica en Ochando o algo así. Recuerda a Brújula. Lite[ratura] moriría de mala manera» (Gil, 6A94). La única publicidad ofrecida fue la que se dio entre la revista y la colección editorial asociada.

Sobrino Vegas ha subrayado la importancia de las colecciones editoriales vinculadas a los productos hemerográficos: «fueron el principal instrumento empleado por editores y colaboradores para darse a conocer y participar en la vida literaria» $(2012,845)$. Ambos proyectos se entendieron como acción conjunta, como «actuaciones complementarias en el marco de un programa editorial bien definido desde el inicio» $(2012,918)$. Así, la promoción mutua de ambos proyectos fue constante. En los números de Literatura se incluyeron notas críticas de todas las publicaciones de la colección hasta el momento. Juan y Leopoldo Panero comentan en el número 4, respectivamente, San Alejo y Fin de semana; Baladas del Quijote e Identidad los reseña Ricardo Gullón en el

${ }^{14}$ Se refiere a la Pen Colección, cuyo primer volumen saldría en mayo de 1934.

15 Sabemos, no obstante, que la revista se vendía al menos en Zaragoza, tal y como refleja una carta de Tomás Seral y Casas (6A238). Es algo, además, evidente, puesto que fue el lugar de residencia de uno de los editores, Ildefonso Manuel Gil, así como la domiciliación de la revista desde su cuarto número. 
último número de Literatura. Del mismo modo, en las solapas de los volúmenes de Pen se incluyeron los sumarios de la revista. En el volumen n. ${ }^{\circ} 11$ (mayo de 1935), de hecho, mucho después de la desaparición de Literatura, todavía figuraba el sumario del n. ${ }^{\circ}$ 5-6.

A partir de octubre de 1934, la distribución de la Pen Colección corrió a cargo de Espasa-Calpe, tal y como aconsejaba Jarnés el 3 de mayo de 1934 (6A3) y a pesar de la opinión de Gil: «Recibí una carta de Jarnés en la que me comunicaba que Pen Colección pasaba a manos -la administración- de EspasaCalpe. Me habéis hecho quedar mal con Sánchez-Cuesta. Y en resumidas cuentas temo que lo hagan peor que él. Que salvo los autores de la casa los demás vayamos al almacén» (6A85). Como en el caso de Literatura, Ildefonso Manuel Gil se preocupa por hacer que Pen se difunda correctamente: busca, por ejemplo, maneras de favorecer su compra por los suscriptores de Literatura proponiendo un descuento del $25 \%$ (6A85) y se interesa por su venta en diferentes eventos literarios: «Leo cosas de la feria del libro. Te veo con Luisa recorriendo los stands. [i]Está Pen Colección?»(6A99). El epistolario hace patente, además, su importante papel en la promoción de la misma: «Y hay que trabajar algo de publicidad. Si voy yo a Madrid verás cómo organizo todo ampliamente» (6A85), que consistió principalmente en el envío de volúmenes a críticos amigos para que los reseñaran en diferentes medios de la capital.

\subsection{Discurso social}

El grueso de la nómina de colaboradores de Literatura lo constituyó el grupo de escritores jóvenes, con una sola mujer, María Zambrano, y, de entre ellos, los vinculados a la red de pequeñas revistas literarias. Son significativas, a este respecto, las palabras de Guillermo de Torre en su Almanaque 1936: «Estos mismos nombres volvemos a encontrarlos reiteradamente en las demás publicaciones afines. Hasta el punto, por tan repetidos, de que en realidad, todas ellas parecen la misma» $(2015,166)$. Junto a ellos, se incluyeron textos de escritores de prestigio (Aleixandre, Guillén, etc.) ${ }^{16}$-algo, por otra parte, totalmente normal en las revistas de estos años (Sobrino Vegas 2012, 919)-, que en muchos casos ejercieron de valedores de la revista: Benjamín Jarnés, por ejemplo (Sobrino Vegas 2012, 919). Así, sus textos se disponían en una situación de privilegio, ocupando siempre las primeras páginas: $1 .^{\circ}$ Benjamín Jarnés; 2. ${ }^{\circ}$ Ángel Sánchez Rivero; María Zambrano; Jorge Guillén; 3. ${ }^{\circ}$ Ramón J. Sender; Max Jacob; 4. ${ }^{\circ}$ Benjamín Jarnés; 5-6. ${ }^{\circ}$ Louis Parrot.

En Literatura hay una ausencia total de praxis cultural asociada a la revista, contrariamente a lo que ocurría con las revistas de la juventud de Gullón,

16 Por el epistolario, además, sabemos que fueron muchos otros los nombres de prestigio que se barajaron entre los posibles colaboradores, como Salinas o Bergamín (Gil, 6A79). 
en Humo, por ejemplo, con su famosa fiesta final en el Casino (Gullón 1985, 30-32). Se pueden destacar únicamente las tertulias que dirigieron los diferentes maestros a cuyo amparo se acogieron los editores -Jarnés, d'Ors- y el viaje que realizaron Maravall, Gil y Gullón en el verano de 1934 a través de la ruta del Cid -de lo que solo ha quedado el testimonio escrito del primero en Castilla o la moral de la creación y unas pocas páginas de la autobiografía inédita de Gullón- con lo que se situaban, significativamente, en la línea noventayochista de un Antonio Machado o un Miguel de Unamuno, tal y como afirma el propio Gullón $(1969,174-175)$. También hay que señalar un homenaje proyectado por el éxito de Literatura del que no sabemos si llegó a realizarse y que Gil, en una carta a Gullón, contempla con ironía: «José Antonio [Maravall] me escribe hoy y dice que vayamos juntos tú y yo a Madrid y nos organizarán un homenaje por el éxito de Literatura. Ya les diré yo que el homenaje consista en suscribirse -si aceptamos mi plan de la carta anterior- por un año de la revista» (6A95).

\subsection{El discurso literario de Literatura}

Uno de los objetivos claros del proyecto Literatura/Pen fue «eliminar el predominio, casi exclusivismo de los poetas, por considerar igualmente legítimo y merecedor de aliento el esfuerzo de los prosistas» (Gullón 1969, 171), por lo que la preocupación por mantener un equilibro entre los diferentes géneros fue constante. De los trece volúmenes de la Pen Colección, en efecto, cuatro son de ensayo, cuatro de narrativa y cinco, finalmente, de poesía. Del mismo modo, en las 68 entradas de Literatura se busca un equilibrio entre géneros -no hay, por ejemplo, secciones que distingan unos de otros, salvo en el caso de las reseñas- que deja, no obstante, algunos desniveles, como es el caso de la prosa narrativa ${ }^{17}$, frente a la crítica o la poesía, por ejemplo. Esta es la distribución exacta de los géneros, que seguiremos como hilo conductor de esta sección: Poesía: 20; Narrativa: 6; Ensayo: 13; Teatro: 1; Reseñas, recensiones y críticas: 28 .

\subsubsection{Poesía}

Así pues, la poesía siguió teniendo una importancia fundamental en la revista. Y, de hecho, era el género que reunía a los nombres de mayor prestigio. En el número 1 aparecía un poema de Gerardo Diego, «Charada», que

17 También el teatro, pero en este caso nunca hubo una pretensión de ofrecer una representación amplia del género. De hecho, solo se publicó una pieza teatral: una farsa basada en los personajes de la Commedia dell'Arte italiana con el nombre de «Paloma o Soledad». La firmaban conjuntamente Ramón Gaya y Antonio Sánchez Barbudo. 
se caracterizaba como un «Homenaje al poeta de Manual de espumas». Es un texto que no abandona la línea creacionista del autor del 27, pero que provoca un cierto efecto de distanciamiento mediante el uso del humor: "Yo pienso en ella y ella no lo sabe / La solución mañana». En el n. ${ }^{\circ} 2$ se incluían dos poemas de Jorge Guillén en la línea pura de Cántico. Y en el n. ${ }^{\circ}$, finalmente, versos en francés de Max Jacob y de Vicente Aleixandre, en su etapa surrealista de preguerra: "Cobra sobre cristal, / chirriante como navaja fresca que deshace a una virgen».

No obstante, fueron los nombres de los jóvenes los que ocuparon el protagonismo de las páginas poéticas de la revista. Solo hubo dos firmas repetidas, la de Ildefonso Manuel Gil (quien, como cofundador de la revista, publicaba en cada número: sus poemas en concreto aparecieron en los números 1, 4 y 5-6) y Pedro Pérez Clotet, que publicó poemas en el n. ${ }^{\circ} 1$ y en el 5-6. El primero se mantuvo a lo largo de toda la revista en la línea neorromántica. Entre los poemas del n. ${ }^{\circ}$, de hecho, se incluía un «Homenaje a los románticos», totalmente claro en cuanto a su orientación poética. Estos textos aparecían dedicados a «Juan Ramón Jiménez, maestro», al que Gil nunca consideró poeta puro. En este mismo número, de hecho, aparece un ensayo de Enrique Azcoaga en que se propone una lectura del poeta moguereño en este mismo sentido: «Con toda la entraña de su vida. Con todo el ímpetu de su alegría serena. Con él; con lo que Juan Ramón dice las cosas». La última colaboración de Gil, finalmente, evidencia una influencia permanente en su poesía, en concreto, y para los poetas de la vía rehumanizadora, en general: Antonio Machado. También el Pedro Salinas de La voz a ti debida, a quien el propio poeta le había dedicado una elogiosa crítica en el $n^{\circ}{ }^{\circ} 2$, está detrás de estos versos de Gil, en arte menor y con preeminencia del sustantivo: «Todo: luz, aires, agua, / colores, tierra, ensueño / se derrumba pesada- / mente sobre mi cuerpo».

Fue esta la línea que siguieron la mayor parte de los poetas que publicaron en Literatura: Pedro Pérez Clotet (1, 5-6), Alfredo Marqueríe (2), Francisco Valdés (3), José María Alfaro (4) y José Ramón Santeiro (4). La mayoría aborda la temática del amor (reflejada incluso en el título de los conjuntos: «Poemas de amor», «Dos poemas de amor», etc.) con referencias, al igual que Gil, al romanticismo, como el caso de la «becqueriana» de Francisco Valdés.

No obstante, el panorama de tendencias poéticas representadas en la revista fue más amplio. En los seis textos de Alfredo Marqueríe seleccionados para el n. ${ }^{\circ} 2$, por ejemplo, aparecen, junto a poemas en la línea del neorromanticismo, otros que recuerdan a las corrientes de vanguardia de los primeros años del siglo XX. Continuarían esta línea, entre otros, Rafael Laffón, quien en el n. 3 ofrece un adelanto de Identidad (Pen, 5), con poemas fundamentados en la imagen y la metáfora, en los cuales «el poeta trata de verter en formas cristalinas su interioridad y de crearse su yo en un lenguaje tal vez demasiado sutil e intelectual» (Cano Ballesta 1996, 186). Leopoldo Panero, en el n. ${ }^{\circ} 3$, 
ofreció tres ejemplos de lo que la crítica ha establecido como su primera etapa de asimilación de los nuevos lenguajes de vanguardia (Huerta Calvo 2007, lxvii): hay muestras, entonces, tanto de poemas de corte guilleniano («jYa soy!: soy ese ejemplo / creado por la fe / en lo que el pecho quiere»), de imágenes creacionistas («Los párpados, febriles / como una hoguera remota sobre la montaña») y de versículo surrealista al estilo de Aleixandre («iQué oscuridad, qué aliento ese bloque de hierro / que se enrojece lentamente / hasta transformar una pluma ávida en la copa alta del chopo!»). En esta misma línea fundamentada en la imagen se sitúa el poema en prosa de Luis Torre: «El eco de mis pensamientos submarinos florece espirales de sal en la espesura y en mi espalda se tejen como juncos las desembocaduras de un enjambre de ríos» (n. $\left.{ }^{\circ} 3\right)$. Tomás Seral y Casas, por último, rinde un homenaje en el n. ${ }^{\circ} 2$ "A Ramón, destorreonado, admirativamente» con una muestra de $\operatorname{chilindrinas}^{18}$, sus particulares greguerías: «El saxofón es el anzuelo del cabaret; la interrogación de la aventura, cayéndose de borracha».

Aunque en menor proporción, Literatura también incluyó en sus páginas algunas muestras de la incipiente literatura comprometida, pese al rechazo que Jarnés había manifestado en el primer texto de la revista. Nos referimos a un poema de Arturo Serrano Plaja («Un hombre o muchos hombres...»), en el número 5-6, que traslucía «el proceso de cambio que la poesía y el proyecto vital del autor estaban experimentando desde el año anterior, con el acercamiento a la AEAR [Asociación de Escritores y Artistas Revolucionarios]» (Sobrino Vegas 2012, 916). Influenciado, además, por el Vallejo de los Poemas humanos, como se ve en su estrofa final: «iMas ay del hombre solo / que no quiera ser hombre, / que renuncie a la tierra por su orgullo, / que su orgullo sea un gesto / de desprecio a los hombres!». En la misma línea, por último, se situaba un soneto de José María Morón, incluido también en el número final de Literatura.

Los cinco volúmenes de poesía de la Pen Colección mostrarían esta misma variedad de tendencias. La poesía neorromántica en el caso de La voz cálida, de Ildefonso Manuel Gil (Pen, 7) y en el de Pedro Pérez Clotet, La sombra de mi vida (Pen, 9). La poesía de ecos puristas en el caso de Identidad, de Rafael Laffón (Pen, 5) -«sabias alquimias poéticas», «verdaderas ecuaciones líricas», lo define Gullón en su reseña en Literatura, n. ${ }^{\circ}$ 5-6- o vanguardistas en El tiempo manual, de Jorge Carrera Andrade (Pen, 12), muy cercano en el tono y en las imágenes empleadas a Poeta en Nueva York. Así como una muestra de

18 Por una de las cartas conservadas del autor sabemos que tuvo interés en publicar una muestra más amplia del género en la Pen Colección. Finalmente, ni se llevó a cabo ni se anunció nunca su aparición, pese a que la propuesta estaba cerrada: «Si tú crees que tiene interés lo de mis Chilindrinas, vamos adelante. Necesito me indiques cuántos ej[emplares] han de hacerse (yo creo suficientes 300)» (6A239). 
poesía neopopular, de clara influencia lorquiana: Entre luna y acequia de Vicente E. Pertegaz (Pen, 13).

\subsubsection{Narrativa}

Como decíamos antes, la narrativa fue uno de los géneros de menor representación en la revista. El más destacado de todos quizás sea el relato «Congregación de las sombras», de Ramón J. Sender, en el n. ${ }^{\circ}$, un adelanto de la novela La noche de las cien cabezas, reseñada en el último número de Literatura. También en el n. ${ }^{\circ} 3$, los editores de la revista publicaban relatos: «Relato», Ildefonso Manuel Gil y «Dámaso y los espejos», Gullón: «son variantes de un mismo tema, pues ambos tratan el fracaso existencial de un personaje que busca alivio o remedio para una contrariedad amorosa en una vida falsa» (Sobrino Vegas 2012, 914).

Gullón, además, ofrecía en el primer número de la revista un adelanto de Fin de semana, segundo volumen de Pen. Ya en Brújula había aparecido otro fragmento de la que sería la primera novela del escritor (.$^{\circ}{ }^{\circ}$ ). La novela, aunque ha planteado cierta controversia respecto a su condición deshumanizada o neorromántica, se sitúa en una línea permeable a las innovaciones de la narrativa europea -con la desaparición del argumento lineal, por ejemplo-, que en España contó con Benjamín Jarnés como uno de sus principales seguidores. Su novela San Alejo, de hecho, se publicó como el primer volumen de Pen, el mismo mes, significativamente, que Fin de semana.

Otros textos narrativos incluidos en Literatura fueron un relato de José Luis Sánchez Trincado (n. ${ }^{\circ}$ ) y un fragmento de las Baladas del Quijote, de Andrés Ochando y Ochando, luego publicado en el cuarto volumen de la Pen Colección.

\subsubsection{Ensayo}

Literatura destacó por incluir, junto a aquellos textos ligados estrechamente con la creación literaria -poesía, narrativa- otros como el ensayo y la crítica, a los que se les daba, además, un estatus similar. El ensayismo en Literatura, pues, tiene una importancia fundamental. Y es precisamente en este campo donde Ricardo Gullón comenzó a destacar como el excelente estudioso de la literatura que sería en los años venideros.

Salvo el caso de los textos ofrecidos por Rafael de Urbano (de tema histórico-cultural), José Ferrater y Mora y María Zambrano (de tema filosófico), todos los ensayos que Literatura incluye son de temática literaria. La línea seguida fue la que iniciara Benjamín Jarnés en «Ejercicios»: defensa de una literatura humana frente a la literatura comprometida y vanguardista, a las que se opone. Ángel Sánchez Rivero, por ejemplo, al hilo de un comentario sobre la cultura clásica, reflexiona sobre el momento literario de las vanguardias en 
esta misma dirección: «La técnica que al principio había sido no más que vehículo para transmitir lo significado absorbe cada vez más la atención y el cuidado del artista [...] En conjunto la humanidad resulta clásica: lo que se dice le interesa en primer término» $\left(n .^{\circ} 2\right)$. En este mismo sentido de literatura como representación de la realidad y de lo humano escriben Louis Parrot en «Jean-Richard Bloch» (n. ${ }^{\circ}$ 5-6): «A la frase perfecta del libro complicado adrede, cuyo secreto es bien pronto aprendido, Bloch prefiere la frase dura, desnuda, sin artificios, plegándose a los contornos rugosos de lo real, cuyo calco debe ser». Y Gullón, en sus dos ensayos sobre autores extranjeros, Gide y Werfel respectivamente: «Caminar primero hacia el interés humano, alcanzarlo, y una vez bien sujeto, entonces, solo entonces, tender la vista hacia el interés literario» (n. ${ }^{\circ}$ ); «No múltiples anécdotas, sino una sola, densa, humana, vital. Pues en las novelas así trabajadas, el hombre aparece desnudo, en su total miseria y en su belleza plena: ser humano y nada más» (n. ${ }^{0}$ 5-6).

Es muy interesante, asimismo, otro conjunto de ensayos en que se abordan obras y autores de la literatura de principios de siglo, pero que se leen en clave rehumanizadora, asimilándolos a la nueva estética. Es el caso del ensayo de Enrique Azcoaga sobre Juan Ramón Jiménez (n. ${ }^{\circ}$ 1), o el texto «Visita a los poetas», de Louis Parrot, en que se valora positivamente el surrealismo, en cuanto forma de indagación en lo humano: «La poesía no tiene otra razón de ser que la de informarnos sobre el hombre [...] Los trabajos médicos, el freudismo, han esclarecido esta zona hasta entonces respetada, donde la poesía actual debe proseguir su exploración y acercarse al misterio de su origen» $\left(\mathrm{n}^{\mathrm{o}}\right.$ $3)$. No faltan, sin embargo, algunos ensayos en que la valoración de las vanguardias y la poesía pura se lleva a cabo sin paliativos, aunque en este caso, y al contrario de lo que ocurría en la poesía, son excepcionales: por ejemplo, un texto de Rafael de Urbano en el n. ${ }^{\circ} 1$ sobre el tropo y la metáfora como elementos esenciales de la creación poética, al hilo de dos modelos literarios, Mallarmé y Góngora.

En la Pen Colección el ensayo constituyó un tercio de las publicaciones e incluyó obras tanto de colaboradores de Literatura: Ángel Sánchez Rivero (Pen, 3) y José Ferrater Mora (Pen, 8), como externos: Fernando Vela con El futuro imperfecto (Pen, 6) y Félix Ros con Una lágrima sobre la Gaceta (Pen, 11).

\subsubsection{Reseñas y críticas}

También tuvieron un gran peso en la revista, por último, los diferentes textos de crítica que hacen repaso de las publicaciones más recientes, con una sección propia desde el n. ${ }^{\circ}$, «Notas», en la que se usaba una tipografía diferenciadora, más pequeña.

Las obras reseñadas fueron variadas en cuanto a géneros, pero centradas, sobre todo, en el círculo de los colaboradores de Literatura, así como en la red 
de los autores de las pequeñas revistas literarias: Ramón J. Sender, Arturo Serrano Plaja, José Luis Sánchez Trincado, Pedro Pérez Clotet, Antonio de Obregón y Jaime Torres Bodet, entre otros. En el último número, además, la sección se dividió en «Libros españoles»y en «Libros franceses». Lo extranjero, de hecho, tuvo cierto peso en la revista, no solo por los dos ensayos de Gullón, antes referidos, sino por las cinco críticas de autores extranjeros que aparecieron en la revista. Los escritores foráneos reseñados fueron Louis Parrot, Charles Péguy, Anne Commène, René Trintzius y Jean Prévost.

Pero lo más interesante de esta sección no es tanto la nómina de obras sino el repertorio que se deduce de la crítica de las mismas, esto es, el «conjunto de normas $[. .$.$] y elementos que gobiernan la producción de textos y sus usos»$ (Pozuelo Yvancos y Aradra Sánchez 2000, 88). No tanto el canon propuesto, pues, sino los criterios de valoración que han conformado ese corpus de obras seleccionadas.

En este sentido, se puede afirmar que, pese a que la poesía y la narrativa publicada en las páginas de Literatura sea variada, los críticos de la revista siguen un criterio de valoración bastante homogéneo, y es el de la necesidad de una vuelta a lo humano en la literatura. Es el caso, por ejemplo, de Leopoldo Panero en su crítica, en el n. ${ }^{\circ}$ 2, de Misery Farm, de Louis Parrot, del que destaca «su volumen ardiente y humano» así como su «inspirado contacto con la sangre profunda del hombre»; en ese mismo número, Azcoaga reseña Sombra indecisa de Serrano Plaja, contraponiéndolo a una poesía anterior, de máscaras y excesiva preocupación por el lenguaje: «Muchos poetas, despreocupados del poeta en absoluto, en los versos vertieron excesiva preocupación. Sin procurarlos con ansia y vista. Sin obstinarse porque los versos se preocuparan del poeta. Del individuo que hasta aquí con los versos, tantas varias caretas se puso» (n. $\left.{ }^{\circ} 2\right)$.

También Ricardo Gullón, en su reseña de Cura Merino, de Eduardo de Ontañón, destaca que ha conseguido «infundir humano aliento cálido» $\left(\mathrm{n}^{\circ} 1\right)$, así como en la crítica que hace de Reloj, de Alfredo Marqueríe, en la que contrapone la nueva poesía humana con el purismo. Sin embargo, Ricardo Gullón supone un caso excepcional en las críticas que hace. Así, junto a textos en que valora la literatura del nuevo romanticismo, hay otros en que defiende la poesía pura. El caso más claro es la reseña de Identidad de Rafael Laffón. Se refiere a la labor del poeta como un «dignificar las cosas a través de alusiones, de contornearlas a su manera purificándose del contacto con lo cotidiano, con lo banal, por medio de sabias alquimias poéticas. El verso es en Laffón duro y difícil, sus poemas verdaderas ecuaciones líricas». Para luego concluir que el disfrute de este tipo de literatura se encamina a «la dificultad vencida, al gozoso deporte de lo difícil, de marchar tras la belleza por sendas apenas desbrozadas para afirmar contentos con el hallazgo, en el encuentro que justifica todo» (n. $\left.{ }^{\circ} 5-6\right)$. 
Mención aparte merece, por último, «la atención prestada a las revistas culturales y literarias» (Sobrino Vegas 2012, 918). Al final de cada sección de «Notas», con la excepción del último número, aparece una recensión de revistas donde se presta especial atención a las jóvenes. Así, junto a Revista de Occidente, Cruz y Raya y Gaceta de Arte, figura el sumario de otras más pequeñas como Isla, Frente literario, Noreste, Ágora o Humano, etc., que son, por cierto, las dirigidas por aquellos con quienes Gullón se cartea y con quienes comparte aspiraciones y proyectos de colaboración. Prueba patente, en fin, de aquello que afirmaba Osuna: «las revistas son productos de intercambio entre grupos [...] Los grupos se reconocen mutuamente, se mutuopromocionan y se alinean en un frente común cultural» (Osuna 2004, 27). De hecho, en el n ${ }^{\circ} 2$ aparecía un texto de Ildefonso Manuel Gil que apuntaba en esta misma dirección: «Verdadera lluvia de revistas, siembra entusiasta que nos hace esperar alegremente una cosecha fértil. Quizás un resurgir pleno de nuestra literatura, una vuelta decidida al abandonado fervor» y reseñaba, en ese mismo artículo, Isla, Frente Literario, Azor, Eco y Noreste. En el último número de Literatura, finalmente, Ricardo Gullón aludía a que «las jóvenes revistas literarias parecen haber enmudecido súbitamente» e instaba a que nuevos proyectos -Hojas de poesía, Atalaya - tomaran el relevo de un ciclo de revistas jóvenes, entre ellas Literatura, que ya se cerraba.

\section{La PROPUeSta estéticA de Literatura}

A través del análisis de las páginas de la revista, pues, se ha podido ver que Literatura no se mantiene ajena al debate estético de la preguerra. Al contrario, en todo momento los editores se sitúan a sí mismos como un grupo de escritores jóvenes que está marcando un cambio de rumbo en la literatura española del momento, hasta entonces protagonizado por el grupo del 27. A estos últimos, además, se les identifica con la estética deshumanizada diagnosticada por Ortega y con la desorientación propia del periodo de las vanguardias. Con el tiempo, de hecho, ellos mismos se incluirían dentro de la generación del $36^{19}$, etiqueta promovida incluso por alguien como Gullón que tan férreamente desautorizaría el uso de este concepto como herramienta ${ }^{20}$. El nuevo camino de la

19 Para una síntesis de la historia del término, vid. Carnero (1989) y Mateo Gambarte (1996, 179-186). Lo que aquí nos interesa, sobre todo, es que ambos, Gullón y Gil, aunque muy en especial el primero $(1959,1965,1969)$ contribuyeron notablemente a la conformación y definición del mismo.

${ }^{20}$ De todas maneras, en uno de sus artículos sobre la cuestión del 36 advierte: «el tal concepto no es clave para resolver problemas de historiografía literaria, sino instrumento (no muy preciso) para fijar posiciones y establecer relaciones entre los escritores de una época», y califica su estudio como «crónica y no crítica» $(1969,162)$. 
rehumanización lo estaban siguiendo tanto los autores del 27 como los jóvenes. Y estos, en su necesidad de autolegitimarse para formar parte del sistema literario, se autodefinen como un nuevo grupo con un programa literario diferente, pero que al final es de continuismo o, al menos, que discurre en paralelo al de los autores consagrados en dicho momento. Desde esta perspectiva, defendieron un programa literario contrario al purismo del 27 y las nuevas tendencias comprometidas y sociales de los años 30. Consistió este en una vuelta al orden después del momento vanguardista: un rechazo a la experimentación formal, y una revalorización de la figuración y de los temas humanos.

No obstante, un análisis en detalle de la revista revela que los propósitos teóricos, tan claros en las formulaciones programáticas, no se cumplían por entero en la práctica. La revista ofrecía, pues, una muestra bastante representativa de las diferentes tendencias de los años 30: purismo (Laffón, Guillén), vanguardias (Panero, Aleixandre), neorromanticismo (Gil, Valdés) y, aunque en menor medida, el compromiso (Serrano Plaja). También Pen daba cuenta de esta variedad.

A esta aparente contradicción es a lo que parece aludir Guillermo de Torre en un comentario general acerca de las jóvenes revistas de 1934: "esta última cosecha de publicaciones ofrece más bien, en su conjunto, un aire sumiso y conformista y, cuando la excepción se quiebra, es solo por el lado de la arbitrariedad inocua» $(2015,166)$. En este mismo sentido, Sobrino Vegas afirma: «ninguna de aquellas revistas había pretendido remover la vida literaria, promover una nueva concepción del arte y la literatura, erigirse como portavoz de una corriente estética o rebelarse contra quienes ocupaban posición de dominio en el sistema literario» $(2012,919)$.

En efecto, la línea que eligieron los nuevos autores fue la de rehuir el espíritu vanguardista de la tradición de la ruptura, como afirma Gullón en un escrito acerca de los autores del 36:

Literariamente, sin aceptar en su totalidad las actitudes (y menos las fórmulas) de los escritores precedentes, no son revolucionarios, ni innovadores, al modo como lo fueron los vanguardistas. Hacia 1935 los ismos estaban perdiendo vigencia. Toda una época de experimentación y aventura quedaba provisionalmente clausurada, en espera de que volviera a abrirse cediendo a nuevos impulsos y distintas oscilaciones del péndulo $(1969,166)$.

Literatura se caracterizó, entonces, por su «espíritu integrador» (Sobrino Vegas 2012, 919), instituyéndose, así, como un punto de encuentro -y, en consecuencia, de tensión- entre diferentes autores y corrientes.

Esta tensión se hace especialmente patente si estudiamos el caso concreto de algunos de los colaboradores de Literatura. Frente a posturas bien delimitadas como la de Ildefonso Manuel Gil, coherente en todos los poemas, relatos y críticas que publica en las tres revistas coeditadas con su amigo, hay otros casos mucho más ambiguos y problemáticos, como el de Ricardo Gullón. El 
crítico se sitúa en ese territorio a medio camino entre una defensa férrea del purismo juanrramoniano y de la apuesta por la nueva vía de la rehumanización $^{21}$. En la reseña que hace de Identidad, de Rafael Laffón, como veíamos antes, por ejemplo, defiende una literatura encaminada «a la dificultad vencida, al gozoso deporte de lo difícil» (n. $\left.{ }^{\circ} 5-6\right)$; mientras que en una nota sobre Reloj, de Alfredo Marqueríe, ataca directamente el purismo: «Una sola línea se estimaba como poesía, como poesía pura, decíase, con ánimo de recalcar y de advertir que fuera de ella no se estimaba posible ese limpio afán que caracteriza el lanzamiento del hombre las alturas» $\left(\mathrm{n}^{\circ}{ }^{0} 4\right)^{22}$.

En definitiva, aunque Literatura es clara en sus formulaciones teóricas, la realidad es que estos jóvenes se vieron en la necesidad de autoprestigiarse mediante el aval de un novelista veterano como Benjamín Jarnés y la inclusión de algunos de los autores del 27 en sus páginas, seguidores de una corriente que, en muchos casos, como el purismo de Jorge Guillén, fue atacada en algunos de los textos de la revista. Además, tampoco la muestra antológica que recoge Literatura es transcripción fiel de sus metatextos, sino que refleja, en cambio, la complejidad del sistema literario español de los años 30, con las tensiones, ambigüedades y contradicciones intrínsecas a su condición de revista literaria.

\section{Conclusiones}

Se ha puesto de manifiesto, pues, el notable interés que tiene la figura de Ricardo Gullón, no solo en su faceta de novelista o crítico -los aspectos, sin duda, que más han interesado hasta ahora- sino en su papel de editor de revistas literarias. Desde su etapa inicial en su ciudad natal, donde junto a sus amigos Luis Alonso Luengo y Leopoldo y Juan Panero -agrupados por Gerardo Diego bajo la denominación de Escuela de Astorga- publica dos revistas de juventud, La Saeta (1925) y Humo (1928); hasta una etapa más madura, entre Soria y Madrid, en la que, de la mano de su inseparable Ildefonso Manuel Gil, publica tres revistas. La primera de ellas fue Brújula (1932), notable por ser el primer intento de un Gullón ya plenamente inmerso en la vida de la capital que

${ }^{21}$ Su posición se definiría a lo largo de la década de los 40 y 50, cuando se sitúa en la vanguardia de la recuperación de la poesía pura desde 1946 (Wahnón 1998, 279), con artículos y libros como «Juan Ramón y la poesía» (1947) y La poesía de Jorge Guillén (1949). Sobre el papel de Gullón en la recuperación de la poética pura en el contexto de posguerra se han ocupado Wahnón (1988, 1998), Navas Ocaña (1995) y Domingo Martín (2019).

${ }^{22}$ En una nota que apareció en Isla sobre el libro se insistía en esta misma dirección: «Pero si este bellísimo Reloj, de Marqueríe, marca tantas y tan variadas horas líricas, puede decirse que todas, en último extremo, alumbran esa hora romántica -o neorromántica- que por lo visto va rigiendo, en nuestros días, muchas de las mejores existencias poéticas» (n. $\left.{ }^{\circ} 6\right)$. 
quiere intervenir en el sistema literario español de los años 30. También es ejemplo primerizo de algo que será una constante en las revistas del crítico: la tensión irresuelta entre las diferentes corrientes estéticas de los años 30 que reflejan sus páginas. Boletín último (1932), su segunda revista en la capital, fue un caso particular en todos los sentidos, desde el llamativo título hasta su propia condición de revista de un solo número y un solo suscriptor. Los textos que recoge son, no obstante, de gran interés, así como su voluntad antológica de esbozar el perfil literario de la nueva generación.

Pero es Literatura (1934), sin duda, la revista más conseguida de todas, en tanto culminación de un intenso proceso al frente de diferentes proyectos editoriales. La lectura del epistolario de Gullón en el archivo de Astorga ha revelado el inmenso cuidado de sus editores por un proyecto mucho más autoconsciente y mejor perfilado que los anteriores: desde la concepción del mismo en 1933 hasta su irremediable final un año más tarde, así como su prolongación en la evolución de la Pen Colección ya en 1935. El estudio en detalle de sus diferentes discursos nos ha permitido, por último, situar Literatura en el módulo hemerográfico de las revistas de la II República y, en concreto, en el intenso debate poético que se estaba produciendo en el sistema literario español de los años 30. La revista, pues, de modo similar a sus predecesoras Brújula y Boletín último, aunque se posiciona a favor de la rehumanización y la llamada al orden después de las revistas de vanguardia, refleja una situación más bien de integración, congregadora de autores de generaciones diferentes y de corrientes estéticas dispares. Más en la línea concreta de Gullón, entonces, a medio camino entre el purismo y la rehumanización, que en la general de $\mathrm{Li}$ teratura, tal y como se desprende de la lectura de sus metatextos.

\section{BIBLIOGRAFÍA CITADA}

Balcells, José María. 2010. «Ricardo Gullón y la generación de 1936». En Ricardo Gullón: crítica literaria y modernidad en la España del siglo XX, ed. Javier Huerta Calvo, 53-66. Madrid: Ediciones del Orto.

Bockus Aponte, Bárbara. 1975. La obra crítica de Ricardo Gullón. Madrid: Ínsula.

Brown, Ann Marie. 1992. Ricardo Gullón (1908-1991). In Memoriam. Granada: UNED.

Cabañas, Teresa. 2002. «La revista literaria: campo de tensiones y estrategias culturales». Proceedings of the 2. Congreso Brasileño de Hispanistas. São Paulo: Associação Brasileira de Hispanistas. http://www.proceedings.scielo.br/scielo.php?script=sci_arttext\&pid $=$ MSC0000000012002000300062\&lng=en\&nrm=iso

Cabañas Bravo, Miguel y Paula Barreiro López, eds. 2013. Ricardo Gullón y la Escuela de Altamira. Astorica 32: 1-228.

Campoamor González, Antonio. 1988. «Bibliografía de Ricardo Gullón». En Testimonio de amistad a Ricardo Gullón, 41-97. Madrid: Taller de Artes Gráficas de Fernández Ciudad.

Cano Ballesta, Juan. 1996. La poesía española entre pureza y revolución (1920-1936). Madrid: Siglo XXI. 
Carnero, Guillermo. 1989. «La generación de 1936... antes de 1936». En Las armas abisinias: ensayos sobre literatura y arte del siglo XX, 249-255. Barcelona: Anthropos.

Domingo Martín, Javier. 2016. «El epistolario de Ricardo Gullón en el archivo de Astorga». Astorica 35: 193-212.

Domingo Martín, Javier. 2020. Las secretas galerías de Ricardo Gullón. Lectura crítica de su epistolario. León: Diputación de León.

Gil, Ildefonso Manuel. 1971. «Ricardo Gullón y la revista Literatura». Ínsula 295: 1 y 5.

Gil, Ildefonso Manuel. 1993. «Prólogo». Literatura, edición facsímil, 3-12. Zaragoza: Diputación General de Aragón.

Gullón, Ricardo. 1959. «La generación del 36». Asomante XV: 64-69.

Gullón, Ricardo. 1965. «La generación de 1936». Ínsula 224-225: 1 y 24.

Gullón, Ricardo. 1969. La invención del 98 y otros ensayos. Madrid: Gredos.

Gullón, Ricardo. 1985. La juventud de Leopoldo Panero. León: Diputación Provincial de León.

Gullón, Ricardo y José Manuel Blecua. 1949. La poesía de Jorge Guillén. Zaragoza: Heraldo de Aragón.

Huerta Calvo, Javier. 2007. «Estudio preliminar» a Leopoldo Panero. En Obra completa, li-cxciv. Astorga: Diputación de León y Ayuntamiento de Astorga.

Huerta Calvo, Javier, ed. 2015. Gerardo Diego y la Escuela de Astorga. Astorga: Centro de Estudios Astorganos Marcelo Macías y Fundación Gerardo Diego.

Huerta Calvo, Javier y Emilia Peral Vega. 2010. «Ricardo Gullón: esbozo de una bibliografía crítica». En Ricardo Gullón: crítica literaria y modernidad en la España del siglo XX, ed. Javier Huerta Calvo, 145-192. Madrid: Ediciones del Orto.

Mateo Gambarte, Eduardo. 1996. El concepto de generación literaria. Madrid: Síntesis.

Navas Ocaña, María Isabel. 1995. Vanguardias y crítica literaria en los años cuarenta. El grupo de Escorial y la Juventud creadora. Almería: Universidad de Almería.

Osuna, Rafael. 1983. «Sociología de la pequeña revista literaria». Boletín cultural y bibliográfico 20 (2): 41-51.

Osuna, Rafael. 1998. Tiempo, materia y texto: una reflexión sobre la revista literaria. Kassel: Reichenberger.

Osuna, Rafael. 2004. Las revistas literarias. Un estudio introductorio. Cádiz: Servicio de Publicaciones de la Universidad de Cádiz.

Pozuelo Yvancos, José María y Rosa María Aradra Sánchez. 2000. Teoría del canon y literatura española. Madrid: Cátedra.

Sobrino Vegas, Ángel Luis. 2012. Las revistas literarias en la II República. Madrid: Universidad Nacional de Educación a Distancia.

Sobrino Vegas, Ángel Luis. 2014. «Las revistas literarias. Una aproximación sistémica». Signa 13: 827-841.

Torre, Guillermo de. 2015. Almanaque literario 1935. Reproducción facsímil de la edición de Madrid: Editorial Plutarco. Sevilla: Renacimiento.

Wahnón, Sultana. 1988. Estética y crítica literarias en España (1940-1950). Granada: Universidad de Granada.

Wahnón, Sultana. 1998. Estética literaria de la posguerra. Amsterdam: Rodopi.

Fecha de recepción: 22 de junio de 2018.

Fecha de aceptación: 5 de septiembre de 2018. 